\title{
A PRÁTICA DE LEITURA ENTRE ALUNOS GRADUANDOS: FOCO NO ARTIGO CIENTÍFICO
}

\author{
Reading Practice Among Undergraduate Students: Focus On The Research Article
}

\author{
Maria Inez Matoso SILVEIRA, UFAL ${ }^{1}$ \\ Fernanda Goulart RITTI-DIAS, UFAL ${ }^{2}$
}

RESUMO: A leitura de artigos científicos é uma prática necessária e de extrema importância na universidade, visto que é um dos gêneros principais para divulgação científica no meio acadêmico. Atualmente, percebe-se, também, uma demanda cada vez maior pela leitura de artigos científicos em língua inglesa, principalmente nos cursos da área da saúde, o que pode se tornar uma barreira para muitos estudantes. Nesse sentido, o presente estudo teve como objetivo traçar o perfil de vinte e oito alunos do curso de educação física de uma universidade pública, quanto à pratica da leitura do gênero textual artigo científico em língua portuguesa e inglesa. Para tanto, foi aplicado um questionário com questões fechadas sobre informações pessoais, características acadêmicas, bem como habilidades de leitura. Os principais resultados da pesquisa demonstraram que o artigo científico é um dos gêneros acadêmicos mais utilizados pelos alunos para busca de conhecimento em suas disciplinas. No entanto, parece que a leitura desses textos na língua inglesa ainda é bastante reduzida. Concluímos, assim, enfatizando a importância de uma familiarização dos alunos universitários com a leitura do artigo científico, em especial em língua inglesa.

PALAVRAS-CHAVE: Leitura; Artigo Científico; Língua Inglesa

ABSTRACT: The reading of research articles has become essential and important in the university, since it is one of the main academic genres. Nowadays, an increasing demand of reading skills in English as a foreign language is also noted, mainly in the health-related courses, which can become a barrier for many students. Thus, the present study has the objective of drawing the profile of twenty-eight physical education students from a public university regarding their reading practice of the research paper in Portuguese and English. Personal information, academic characteristics, as well as reading abilities were collected by means of a questionnaire. The main results of this study revealed that the research paper is the most used genre by the students in their disciplines. However, it seems that there is little contact with English reading among these students. We conclude, thus, emphasizing the importance of a familiarization of university students with the research article, especially those written in English.

KEYWORDS: Reading; Research Article; English Language

\footnotetext{
${ }^{1}$ Doutora em Linguística pela Universidade Federal de Pernambuco e professora adjunta da Universidade Federal de Alagoas.

${ }^{2}$ Mestre em Educação pela Universidade Federal de Alagoas (UFAL)
} 


\section{INTRODUÇÃO}

A leitura é uma das habilidades essenciais para o processo ensino-aprendizagem em todas as fases da escolarização, e com mais intensidade, na universidade, pois é principalmente por meio dela que se dá o acesso ao conteúdo das diversas disciplinas (CASTELLO-PEREIRA, 2003). No entanto, a pouca familiaridade com o discurso científico ou acadêmico parece limitar a leitura de alunos do ensino superior (FIGUEIREDO, 1985), visto que o texto científico não é de leitura fácil nem costumeira para os estudantes. Como atividade intelectual, a leitura do discurso científico exige uma postura crítica por parte de quem o produz, como também de quem o lê (TANZAWA, 2009).

Assim como qualquer outro gênero textual, a leitura do texto científico requer o domínio de habilidades específicas, dentre elas, a capacidade de identificar a organização textual, ou seja, a estrutura ou organização retórica do texto, os conceitos básicos do tema/área de conhecimento tratado no texto e uma familiarização mínima da linguagem científica. Vale ressaltar que existem vários gêneros científicos ou acadêmicos e cada um possui uma função específica na academia.

Para Swales (1990), o principal gênero acadêmico é o artigo científico (AC). E, aliado ao AC, vem a necessidade da habilidade da leitura em língua inglesa, já que grandes pesquisadores do mundo todo estão publicando cada vez mais os seus trabalhos em revistas internacionais de prestígio veiculados na língua inglesa (HYLAND, 2006 ). O crescimento do inglês como principal língua de disseminação de conhecimento científico tem transformado as experiências educacionais de inúmeros alunos, que devem agora ganhar fluência nas convenções dos discursos acadêmicos redigidos na língua inglesa para aprofundar os conhecimentos relativos às suas áreas de estudo (HYLAND, 2002).

Apesar da reconhecida importância desse gênero textual na academia, poucos estudos foram realizados para entender as práticas de leitura de ACs entre alunos universitários . Assim, o objetivo desse estudo foi verificar a familiaridade de 28 graduandos com o gênero textual AC em português e inglês. Apresentaremos, primeiramente, a importância do AC na universidade, com foco nas suas interrelações com os outros gêneros acadêmicos. Em seguida, fazemos a descrição da pesquisa seguida das análises e discussão dos dados coletados. 


\section{O ARTIGO CIENTÍFICO E A SUA IMPORTÂNCIA NA UNIVERSIDADE}

Vários estudos têm se dedicado a estudar o artigo científico sob diferentes aspectos, como resultado da sua crescente relevância na comunidade acadêmica (BERNARDINO, 2007; RITTIDIAS E SILVEIRA, 2011; SANCHES, 2009a; SANCHES, 2009a; ZILIO ET. AL., 2009). Swales (1990), educador e linguista aplicado, cuja produção é reconhecidamente voltada para aplicações em análise de gêneros em contextos acadêmicos, afirma que o principal gênero acadêmico é o AC. Segundo o autor, isso se deve primeiramente ao reconhecimento e uso difundido desse gênero no meio acadêmico. Além disso, o AC possui uma relação dinâmica com todos os outros gêneros que circulam na academia, dentre eles, os resumos, as dissertações e teses, as apresentações, as propostas de financiamento, as monografias ${ }^{3}$ e os livros. Essa relação foi representada pelo autor, como mostra a figura abaixo:

Figura 1. Modelo "spider's web", proposto por Swales (1990, p. 117). O AC estabelece relações com os outros gêneros acadêmicos.

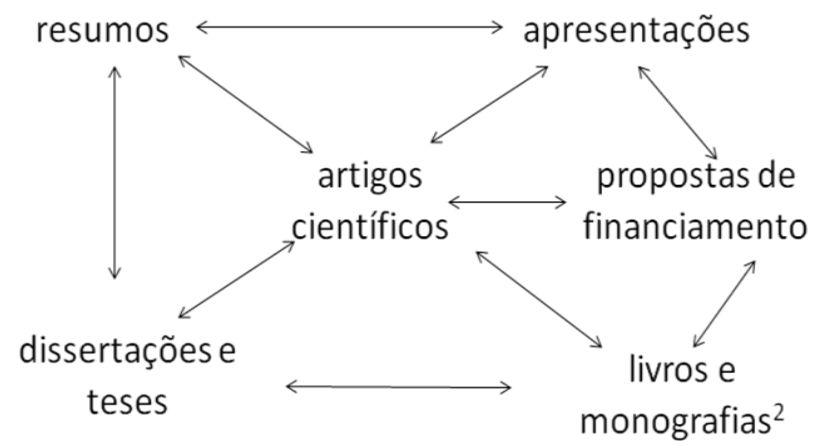

As interrelações entre o $\mathrm{AC}$ e os gêneros presentes nessa "teia" são descritas pelo autor. Por exemplo, quanto à relação entre o AC e resumos, Swales enfatiza que, na maioria das vezes, as revistas exigem a redação de um resumo cujo objetivo principal é guiar o leitor até o texto principal, no caso o AC. Além disso, para o envio de trabalhos em eventos, por exemplo, o resumo é exigido para que o trabalho seja avaliado pela comissão científica. Quando se trata de propostas

\footnotetext{
${ }^{3}$ Monografia (tradução de Monograph), em inglês, não se trata de um trabalho final de graduação, termo comum no Brasil, mas sim de um estudo detalhado sobre um assunto único, geralmente na forma de um livro curto (Oxford University Press, 2000).
} 
de financiamento, o AC representa papel importante, pois, muitas vezes, as chances de se conseguir recursos financeiros aumentam de acordo com a quantidade de ACs publicados pelo pesquisador. O inverso também é verdadeiro. Por exemplo, quando o pesquisador consegue grandes financiamentos, suas chances de publicar aumentam consideravelmente.

Nessa mesma obra, Swales descreve a organização retórica do gênero AC, apresentando quatro unidades retóricas básicas: Introdução, Métodos, Resultados e Discussão. Segundo o autor, dependendo da área de estudo, essas unidades podem sofrer alterações. Por exemplo, na área de humanidades é muito comum a inexistência da seção de metodologia, haja vista a natureza ensaística de alguns dos artigos dessa área.

O AC pode ser definido como sendo um texto escrito (embora frequentemente contenha elementos não verbais), geralmente com um número limitado de palavras, que tem como objetivo relatar uma investigação feita por seus autores ou outros autores. Além disso, pode visar examinar questões teóricas e/ou metodológicas. O AC é um gênero complexo, especificamente moldado para ganhar aceitação da comunidade acadêmica, conforme Swales (1990, p.93).

Hyland (apud BERNARDINO, 2007, p. 40) pontua, ainda, como objetivos do gênero AC: estabelecer a produção científica como uma novidade para a comunidade disciplinar; reconhecer produções anteriores e estabelecer as hipóteses em questão dentro do contexto geral do discurso disciplinar; oferecer garantias sobre as proposições construídas no artigo; demonstrar um ethos disciplinar apropriado e habilidade para negociar com os pares na academia.

Convém salientar que o conhecimento da estrutura do gênero textual, bem como de suas práticas retóricas e discursivas não se desenvolvem espontaneamente entre os alunos universitários de graduação, salvo raras exceções. Dessa forma, se faz necessário um maior envolvimento e familiarização desses alunos com os gêneros acadêmicos em suas disciplinas, dentre eles o AC, de forma a instrumentalizá-los para uma prática de leitura e de lectoescritura que melhorem o seu letramento acadêmico (RITTI-DIAS; SILVEIRA, 2011).

\section{DESCRIÇÃO DA PESQUISA}

Participaram do estudo 28 alunos do curso de graduação de Educação Física de uma universidade pública de Pernambuco, região Nordeste do Brasil. Um questionário com questões fechadas contendo informações pessoais, características acadêmicas, bem como habilidades de 
leitura foi aplicado pelos pesquisadores em apenas uma sessão. Escolhemos utilizar o questionário por ser um instrumento válido para obtenção de uma série de informações, sobretudo aqueles de ordem pessoal, motivo pelo qual usamos esse instrumento no presente estudo.

Utilizamos uma abordagem quantitativa observacional transversal, em que obtivemos quantitativamente as informações dos sujeitos em uma única ocasião. Foi por este motivo que optamos por questões fechadas, que nos permitiu quantificar mais claramente as informações coletadas, fornecendo assim a respostas necessárias para a análise do nosso objetivo. Os dados foram tabulados em planilha Excel e analisados mediante estatística descritiva.

Escolhemos alunos que estavam cursando uma disciplina eletiva sobre saúde em que existe, atualmente, grande corpo de evidência sendo disponibilizados na literatura. Especialmente na área de Educação Física o conhecimento sobre o assunto é muito atual e a leitura de artigos é uma das principais formas de obtenção das informações. Estavam fazendo parte da disciplina alunos que se encontravam a partir do quarto período da graduação. O professor responsável pela turma permaneceu presente na sala de aula durante a coleta de dados.

Os sujeitos foram informados dos objetivos da pesquisa e aqueles que concordaram em participar como voluntários assinaram o termo de consentimento livre e esclarecido. O projeto foi aprovado pelo comitê de ética da Universidade Federal de Alagoas, Protocolo número 0076062011-88.

\section{RESULTADOS E ANÁLISES}

Dos 28 estudantes pesquisados, a maioria era do sexo feminino (71\%). Metade dos graduandos (50\%) afirmou não estar trabalhando. Com relação à faixa etária dos participantes, 53\% tinham 22 anos ou menos, 39\% estavam na faixa entre 23 e 30 anos e apenas $8 \%$ dos alunos tinham mais de 30 anos.

Os sujeitos pesquisados encontravam-se acima do quarto período da graduação ${ }^{4}$ (Tabela 1). Todos os alunos já haviam cursado a disciplina Metodologia da Pesquisa, e por isso esperava-se que já possuíssem maior contato com a linguagem científica e alguns dos principais gêneros acadêmicos. A partir do sétimo período (em que estavam inseridos 53\% de nossos participantes), as leituras são intensificadas devido à necessidade da produção do trabalho de conclusão de curso, exigido para os alunos dessa universidade, que podem ser apresentadas no formato tradicional de

\footnotetext{
${ }^{4} \mathrm{O}$ curso pesquisado é composto por oito períodos, ou seja, quatro anos.
} 
monografia, ou em formato de artigos científicos, justificando mais uma vez o contato que se espera desses alunos com esse gênero acadêmico.

Tabela 1. Características acadêmicas dos alunos

\begin{tabular}{lc}
\hline Informações coletadas & $\begin{array}{c}\text { Porcentagem de alunos } \\
(\boldsymbol{\%})\end{array}$ \\
\hline Período da graduação & - \\
$5^{\circ}-6^{\circ}$ semestre & 43 \\
$7^{\circ}-8^{\circ}$ semestre & 53 \\
Acima do $9^{\circ}$ semestre & 4 \\
Aluno de iniciação científica & \\
Sim & 29 \\
Não & 71 \\
Principal fonte de pesquisa acadêmica & \\
Livros & 50 \\
Periódicos & 42 \\
Internet & 4 \\
Outros & 4 \\
Inglês em instituto de idiomas & \\
Sim & 46 \\
Não & 54 \\
Idioma para pesquisas acadêmicas & \\
Português & 96 \\
Inglês & 4 \\
Espanhol & 0 \\
Outro & 0 \\
\hline
\end{tabular}

Outro bom indicador de familiaridade com os gêneros e discurso científico é a realização de iniciação científica. A participação desses alunos em grupos de estudos exige, sem dúvida, maior contato com diversos gêneros acadêmicos, sejam escritos ou orais, como relatórios de pesquisa, resumos, resenhas, apresentações em congressos, participação em seminários, entre outros.

Como mostra a Tabela 1 acima, 29\% dos alunos foram alunos de iniciação científica.

Dos oito alunos que afirmaram ter participado como alunos de iniciação científica, apenas um relatou ter habilidade regular de leitura de artigo em língua portuguesa. Os sete restantes relataram serem leitores bons ou excelentes. Isso pode estar relacionado ao maior contato com a leitura que é exigida desses alunos. Por outro lado, quanto à língua inglesa, apenas um relatou ter boas habilidades, enquanto que os sete restantes afirmaram serem leitores regulares.

\footnotetext{
${ }^{5}$ São os alunos que, por algum motivo, não terminaram o curso ao fim do oitavo período e estavam cursando a disciplina.
} 
Ao serem questionados sobre a principal fonte de leitura que utilizam para adquirir conhecimento nas suas disciplinas, $50 \%$ dos alunos responderam como sendo o livro. Em segundo lugar ficou o artigo científico (42\%).

Um pouco mais da metade dos alunos pesquisados (54\%) relataram nunca ter estudado inglês em instituto de idiomas (Tabela 1). Isso pode ser um indicativo da pouca familiaridade desses estudantes com a língua inglesa, a não ser o adquirido no dia-a-dia informalmente ou aquele adquirido no ensino fundamental e médio. Sabendo que uma boa parte dos pesquisadores do mundo, falantes ou não da língua inglesa, publica artigos em inglês para maior visibilidade e reconhecimento de suas pesquisas (HYLAND, 2006), a aquisição de conhecimento dos alunos que só utilizam a língua portuguesa na academia acaba tornando-se bastante limitada.

Segundo os dados da presente pesquisa, 96\% dos alunos avaliados utilizam a língua materna como principal idioma para pesquisas acadêmicas. Interessantemente, os sujeitos do presente estudo acreditam que saber inglês na graduação é muito importante (80\%) ou importante $(20 \%)$.

Quando questionados sobre as habilidades de leitura de AC em língua portuguesa, a maioria dos alunos relatou serem bons leitores (61\%). No entanto, ainda existe um número significativo de alunos que se auto-avaliaram como leitores regulares de AC em português (29\%). Castello-Pereira (2003, p. 18) aponta que "a dificuldade de leitura no ensino universitário parece ser decorrente do desconhecimento do universo discursivo e da estrutura diferenciada que os textos acadêmicos apresentam", e enfatiza que o aluno necessita aprender a ler esses textos e não esperar que essa habilidade se desenvolva espontaneamente.

Quase a metade dos alunos (43\%) se auto-avaliaram como leitores péssimos de AC em língua inglesa. Isso pode ser reflexo da pouca familiaridade e estudo da língua inglesa desses alunos, e, como consequência, resultando no baixo número de artigos em inglês lidos na semana que antecedeu a pesquisa $(93 \%$ dos alunos que relataram não ter lido nenhum AC em língua inglesa). Por outro lado, 39\% dos alunos relatou ter lido entre 2 e 4 artigos em português na mesma semana, o que, como já citado anteriormente, pode ser estar relacionado ao período de graduação em que esses alunos se encontram. 
Tabela 2. Habilidades de leitura

\section{Informações coletadas}

\section{Porcentagem de}

alunos $(\%)$

\section{Como você avalia a sua habilidade de leitura de AC em português}

Excelente

Bom

Regular

Ruim

Péssimo

Como você avalia a sua habilidade de leitura de AC em inglês

Excelente

Bom

Regular

Ruim

Péssimo

Quantos artigos em português você leu na última semana?

0

1

Entre 2 e 4

Mais de 4

Quantos artigos em inglês você leu na última semana?

0

Entre 2 e 4

Mais de 4

Por fim, questionamos sobre as maiores dificuldades que esses alunos encontram durante a leitura de AC em inglês. O vocabulário técnico (45\%) e a linguagem científica (27\%) foram as dificuldades mais citadas (Tabela 3). Assim, é possível afirmar que, além de da necessidade do estudo da língua inglesa, uma maior familiarização com a leitura de diferentes gêneros acadêmicos também parece ser uma necessidade desses alunos.

Tabela 3. Dificuldades durante a leitura de artigo científico em língua inglesa

\section{Qual é a sua maior dificuldade durante a leitura de AC em língua inglesa}

\section{Porcentagem de alunos}

(\%)

O vocabulário técnico

45

A linguagem científica

27

A gramática

18

Outro- Não sei inglês

8

$\mathrm{O}$ assunto 


\section{CONSIDERAÇÕES FINAIS}

A partir dos resultados do presente estudo, pudemos relatar que, apesar do livro ainda ser a fonte de pesquisa predominante da maioria dos sujeitos estudados, o artigo científico tem espaço importante nesse curso de graduação. No entanto, quando se trata da língua inglesa, parece que esses alunos ainda estão relutantes, apesar da consciência da sua importância para o sucesso na graduação. Esse distanciamento com o idioma estrangeiro pode ser uma barreira para esses alunos, impedindo que realizem suas pesquisas em periódicos internacionais cuja língua oficial é o inglês. Futuros estudos seriam importantes para entender o porquê dessa falta de contato e busca pelo aprendizado da língua inglesa.

Podemos concluir enfatizando que alguns aspectos relacionados à compreensão de textos, à leitura para estudo e os diferentes gêneros textuais acadêmicos, em especial o artigo científico, são de grande relevância prática para a academia. Dessa forma, atividades que promovam um grau mais elevado de compreensão e apropriação dos conteúdos veiculados pelos textos, tanto em língua materna quanto em língua inglesa, devem ser elaboradas e inseridas como parte integrante dos currículos da graduação para esses alunos.

\section{REFERÊNCIAS BIBLIOGRÁFICAS}

BERNADINO, C.G. O metadiscurso interpessoal em artigos acadêmicos: espaço de negociações e construção de posicionamentos. Tese de doutorado. Belo Horizonte/MG UFMG, 2007.

CASTELLO-PEREIRA, L. T. Leitura de Estudo: ler para aprender a estudar e estudar para aprender a ler. Campinas: Alínea, 2003.

FIGUEIREDO, C.A. A organização textual e o ensino da leitura em inglês. Ilha do Desterro, p. 47-56, 1985.

HYLAND, K. EAP: issues and directions. Journal of English for Academic Purposes. v.1. p.112, 2002.

Routledge, 2006.

English for Academic Purposes: An Advanced Resource Book. New York: RITTI-DIAS, F.G e SILVEIRRA, M.I.M. Reflexões acerca da leitura para estudo e leitura do texto científico na universidade. In: Anais do VI Encontro de Pesquisa em Educação de Alagoas, Maceió, AL, 2011. Disponível em: http://www.epealufal.com.br/anais/. Acesso em: 15 out. 2011. ISSN: $1981-3031$.

SANCHES, K. P. A normatização do artigo científico e a estabilidade do gênero. Estudos linguísticos, São Paulo, v.38, n.3, set.-dez. 2009, p.165-179,

Interdiscursividade em artigos científicos. In: GARCIA, B.R.V.; CUNHA, C.L.; PIRIS, E.L.; FERRAZ, F.S.M.;GONÇALVES SEGUNDO, P.R. (Orgs.). Análises do Discurso: o diálogo entre as várias tendências na USP. São Paulo: Paulistana Editora, 2009. 
SANTOS, E. C. P. dos. Compreensão de leitura : aplicação da técnica de cloze em estudantes universitários. Intellectus - Revista Acadêmica Digital das Faculdades Unopec -Ano 02, nº 04, jan./jul. 2005

SWALES, J. M. Genre analysis: English in academic and research settings. Cambridge: Cambridge University Press, 1990.

TANZAWA, E.C.L. Leitura e compreensão de textos acadêmicos: um estudo junto a alunos de dois cursos de graduação. 2009. 132p. Dissertação (Mestrado em Educação) -Universidade Estadual de Londrina.

ZILIO et. AL. Artigos científicos de Cardiologia: contraste de macro e microestruturas para caracterização de tipo textual. In: Anais do V SIGET, Caxias do Sul, RS, 2009. ISSN: 18087655 . 